\title{
What is the best core measure after critical illness when the IES-R is no longer accessible for new researchers?
}

\author{
Reba Umberger(i)
}

\section{This comment refers to the article available at https://doi.org/10.1186/s13054-019-2553-z}

\section{Dear Dr. Vincent,}

The recent publication by Hosey et al. regarding validation of the Impact of Event Scale- 6 to screen for posttraumatic stress disorder (PTSD) in ARDS survivors is an important contribution for research on outcomes after critical illness [1]. PTSD is one possible manifestation of post-intensive care syndrome which may occur and impact long-term outcomes after critical illness [2]. Experts in long-term outcome by consensus have recommended the Impact of Event Scale-revised (IES-R) as one core outcome measure for mental health following critical illness [3]. Hosey et al. conducted a secondary analysis of 1001 ARDS survivors with IES-R measures at multiple points over 5 years and validated a shorter 6-question version [1]. The IES-6 includes 2 questions for each PTSD domain based on DSM-IV criteria (see Fig. 1). This shortened version will greatly reduce the screening burden on participants; however, the authors also recommend longitudinal administration of both the IES-R and the IES- 6 after critical illness to address stability of the measure using test-retest reliability. Unfortunately, the IES-R scale has been retired by the developer due to revisions in PTSD criteria, limiting its use to investigators with ongoing research or prior permission (personal communication with Dr. Weiss,
August 12, 2019). While the IES-R does not fully align with the DSM-V criteria, it aligns with three criteria. The PTSD Checklist for DSM-5 (PCL-5) has been recommended as a screening measure of PTSD and adopted by the National Center for PTSD. The PCL-5 aligns fully to DSM-V criteria and includes questions to assess for negative alterations in cognition and mood (e.g., blame, negative emotions) [4] which are not assessed by the IES-R or IES-6. The importance of this new PTSD symptom cluster is unknown after critical illness. Researchers should use the most reliable and valid instruments available at the time their research is designed. The PCL-5, a 20-question instrument, has not yet been validated in ICU populations [5]. More work will be needed in the future to validate the PCL-5 in ICU populations and to create and validate a shorter version to reduce the burden on participants.'
Sincerely,
Reba Umberger, PhD, RN, CCRN-K
Assistant Professor of Nursing
University of Tennessee Health Science Center
Department of Acute and Tertiary Care 


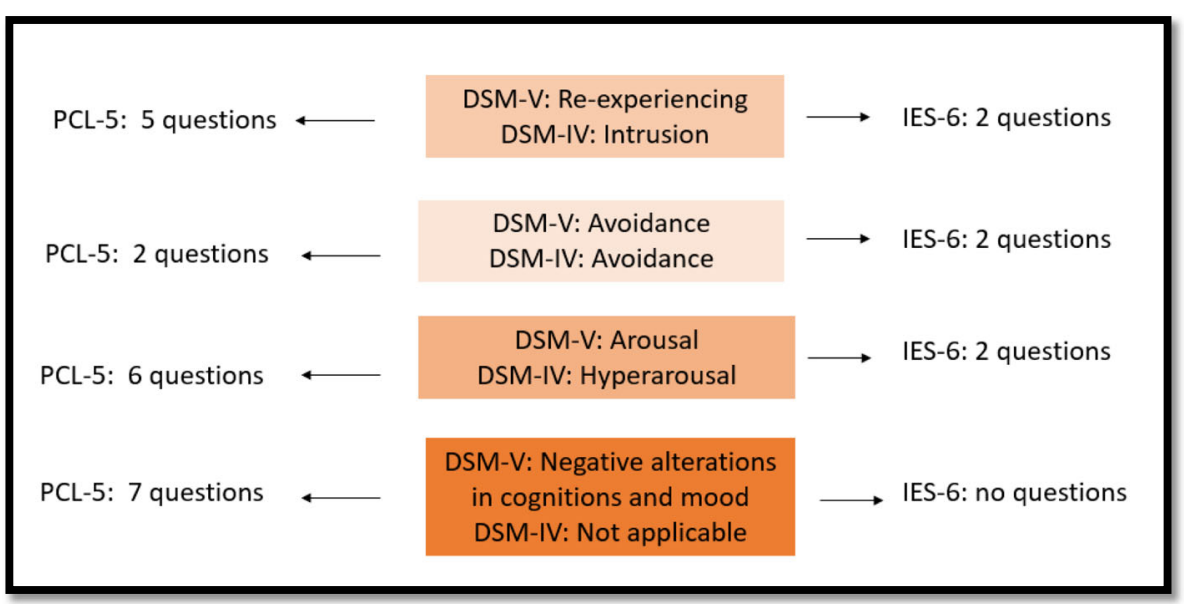

Fig. 1 Comparison of PCL-5 and IES-6 questions addressing PTSD criteria. Note: Current DSM-V criteria are shown with analogous DSM-IV criteria which were used to develop the IES-R and hence the IES-6

\section{Acknowledgements}

The author thanks Mr. Curtis Roby for his editorial assistance and Drs. Mona Wicks and Ansley Stanfill for their helpful comments.

\section{Author's contributions}

The author read and approved the final manuscript.

\section{Author's information}

The topic of this letter arose when trying to obtain the IES-R for an intramurally funded project.

\section{Funding}

The author has intramural funding by the University of Tennessee Health Science Center College of Nursing.

\section{Availability of data and materials}

Not applicable.

\section{Ethics approval and consent to participate}

Not applicable.

\section{Consent for publication}

Not applicable.

\section{Competing interests}

The author declares that she has no competing interests.

Received: 22 August 2019 Accepted: 2 September 2019

Published online: 13 September 2019

\section{References}

1. Hosey MM, Leoutsakos JS, Li X, Dinglas VD, Bienvenu OJ, Parker AM, Hopkins RO, Needham DM, Neufeld KJ. Screening for posttraumatic stress disorder in ARDS survivors: validation of the Impact of Event Scale-6 (IES-6). Crit Care. 2019:23:276-83.

2. Needham DM, Davidson J, Cohen $H$, Hopkins RO, Weinert C, Wunsch $H$, Zawistowski C, Bemis-Dougherty A, Berney SC, Bienvenu OJ, Brady SL, Brodsky MB, Denehy L, Elliott D, Flatley C, Harabin AL, Jones C, Louis D, Meltzer W, Muldoon SR, Palmer JB, Perme C, Robinson M, Schmidt DM, Scruth E, Spill GR, Storey CP, Render M, Votto J, Harvey MA. Improving longterm outcomes after discharge from intensive care unit: report from a stakeholders' conference. Crit Care Med. 2012:40:502-9.

3. Dinglas VD, Faraone LN, Needham DM. Understanding patient-important outcomes after critical illness: a synthesis of recent qualitative, empirical, and consensus-related studies. Curr Opin Crit Care. 2018;24:401-9.
4. Blevins CA, Weathers FW, Davis MT, Witte TK, Domino JL. The Posttraumatic Stress Disorder Checklist for DSM-5 (PCL-5): development and initial psychometric evaluation. J Trauma Stress. 2015;28:489-98.

5. Bovin MJ, Marx BP, Weathers FW, Gallagher MW, Rodriguez P, Schnurr PP, Keane TM. Psychometric properties of the PTSD Checklist for Diagnostic and Statistical Manual of Mental Disorders-Fifth Edition (PCL-5) in veterans. Psychol Assess. 2016;28:1379-91.

\section{Publisher's Note}

Springer Nature remains neutral with regard to jurisdictional claims in published maps and institutional affiliations. 